RESEARCH REPORT

\title{
CORRELATION BETWEEN LOW BACK PAIN AND RECTUS ABDOMINIS MUSCLE WEAKNESS USING KENDALL'S GRADING SCALE
}

\begin{abstract}
\section{BACKGROUND}

Kendall's approach is used to test the muscles strength and to determine the correct alignment of the muscle fibers. The major causes of back pain are work related problem, mechanical stress on muscles and faulty postures, which leads to core muscle weakness particularly rectus abdominis or may cause DRA. Thus the study aims to identify a causal relationship between low back pain and rectus abdominis muscle weakness using Kendall's grading scale.
\end{abstract}

\section{STUDY DESIGN}

Cross Sectional Study

\section{SAMPLING TECHNIQUE}

Non-probability convenience sampling technique

\section{METHODOLOGY}

142 (men $33.80 \%$ and women $66.20 \%$ ) participants with low back pain were recruited in the study. The Kendall grading scale test the strength of muscles of the upper and lower rectus abdominis muscles among the participants while self-administered questionnaire was used to identify the nature of the back pain.

\section{RESULT}

Sperman's rho coefficient of correlation was applied to find out the cause effective correlation between the two variables, result shows no significant cause effective correlation between the upper and lower back pain and lower rectus abdominis muscles weakness ( $P>0.05)$ with $r=0.065$ and $r=0.031$ respectively.

\section{CONCLUSION}

Although core muscle weaknesses are the source of back pain but no significant cause effective correlation exist between the two variables in this study.

\section{KEYWORDS}

Rectus Abdominis, low back pain, Kendall's grading scale, Numeric Pain Rating Scale, Spearman's correlation, Abdominal Strength test.

\author{
Urooj Khan \\ Lecturer \\ Dow IPM\&R \\ pisceszbgrl@hotmail.com \\ Sana Kayenat \\ Physiotherapist \\ ACELP \\ sanakayenat@gmail.com

Khadija Usman
Physiotherapist
ACELP
khadija_usman@ymail.com
Vinesh Kumar
Physiotherapist
Aga Khan University Hospital
vinesharyaveer@gmail.com

[Khan U, Kayenat S, Usman K, Kumar V. Correlation Between LBP and Rectus Abdominis Muscle Weakness Using Kendall's Grading Scale. Pak. j. rehabil. 2017;6(2):38-44] 


\section{INTRODUCTION}

Back pain considers expensive disease in modern society'. It is job related complaint ${ }^{2}$. Most people experience low back pain (LBP) at some point throughout their life span ${ }^{3}$. In United States, the economic burden of disease ranges from 84 to 624 dollars per year ${ }^{4}$. The prevalence has been reported from $6 \%$ to $19 \%$ for a first episode and recurrence achieves up to $50 \%$ over a 5 years' stage $^{5}$. In the Western countries, back pain lifetime prevalence is $60 \%-80 \%$ among adult population'. The incidence increases with age and is more prevalent between 30 to 50 years, thus associated with increased health care expenditures around the world ${ }^{7}$. The prevalence of back pain in Bangladesh is $64.8 \%$, in India is $19.8 \%$, in Nepal is $69.5 \%$, in Pakistan is $40.6 \%$ and in Sri Lanka is $36.2 \%{ }^{6}$. The general prevalence is higher in females $(48 \%)$ than in males $(32 \%)^{8}$.

Low back pain is defined as a pain or discomfort located below the margin of the 12th rib and above the inferior gluteal fold, with or without leg pain?. Back pain can be classified into acute (less than six weeks), subacute (6 to 12 weeks) or chronic (longer than 12 weeks) ${ }^{4}$. Faulty posture and biomechanics amendment are precursor to low back pain development ${ }^{10}$. Faulty posture is often associated with weak abdominal muscle ${ }^{11}$. Dysfunction of abdominal musculature (internal oblique and rectus abdominis) is one of the major causes of chronic low back pain (CLBP). The muscles of abdomen averagely enhanced activation by $1-3 \%$ and the extensors enhanced by $13-31 \%$, due to increased load in CLBP ${ }^{12}$. Rectus abdominis (RA) eccentric activity is crucial to support the trunk and evade too much spinal strain and back pain ${ }^{13}$.

Diastasis recti abdominis (DRA) is an injury measured by a midline parting of the 2 rectus abdominis, this decrease strength of rectus abdominis. DRA occur $30 \%$ to $70 \%$ in pregnant women. DRA also seen in males. Condition is the consideration to be related with growing age, hereditary weakness of the abdominal muscles, weight lifting, weight fluctuations, performing full sit-ups, intermittent or chronic abdominal distention, and actions that may stimulate immense intra-abdominal pressure ${ }^{14}$. Kendall's Abdominal Strength test is a standard method to assess abdominal strength in physical therapy ${ }^{15}$.

In Kendall's abdominal strength test subjects lie supine on a firm surface with arms folded across the chest; a tester assists in raising the legs up to a vertical position, keeping the knees straight, then perform a posterior pelvic tilt and maintain this position while slowly lowering the legs to horizontal, strength is graded on the ability to keep the low back flat on the surface, the angle at which the back arches is noted and correlated with Kendall's grading system ${ }^{15}$.
The rationale of this study is to find prevalence or contribution of rectus abdominis weakness in back pain patients. This study will contribute to decreasing the incidence of preventable impairments in population. The purpose of rectus abdominis weakness tests in backache patients is to find strength of rectus abdominis in back pain patients. It will determine is rectus abdominis weakness could be cause of back pain.

Deenika conducted systemic review in which eight studies were included. All the studies incorporated abdominal/core strengthening muscle exercises. The study resulted that exercises done during antenatal period reduced DRAM by $35 \%^{16}$.

A study on Effects of Basic Strength and Pelvic training on high school cross-country race times. He performed four standardized isometric strength test at hip adductors, abductors, extensors and core musculature for six weeks. He concluded that there was no interaction regarding increasing muscle strength and decreasing race times. Pelvic and core stability strengthening program routine trice a week could decrease in race times ${ }^{17}$.

A study conducted on finding out the occurrence of diastasis of rectus abdominal muscles instantly postpartum, having an outcome with the high occurrence of DARM (68\%) on top of the umbilicus. A DARM of above $2.5 \mathrm{~cm}$ is measured unsafe as it may hinder with the muscles of abdomen capability to stabilize the trunk, deprived lumbar stabilization may influence the person to the increase the development of back pain ${ }^{18}$.

Greta conducted the pilot study on 63 children and concluded that there is increased incidence of low back pain that has been related with Lumbar lordosis, especially in women. The posture stretches and weakens the abdominals (rectus abdominis, external and internal oblique) while shortening the hip flexors and lumbar extensors imbalance increases the stress to the low back, resulting in pain. He conducted Kendall's lower abdominal and Kendall's upper abdominal test to check the strength of rectus abdominis muscle. He concluded that strengthening exercises of rectus abdominis could delay back pain ${ }^{15}$.

Patricia, concluded in his article about Risk factors and occurrence of diastasis recti abdominis from late pregnancy to 6 months postpartum and a relationship with lumbo-pelvic pain, that diastasis recti abdominis is not linked with lumbo-pelvic pain $^{14}$.

Study naming Correlation of low back pain and diastasis rectus abdominis in post-menopausal women between the age group of $50-60$ years, resulted that there was a partial positive correlation between diastasis of abdominis and Low back pain 
in post-menopausal women. They used VAS and Roland Morris questionnaire for disability and pain and assessed for diastasis recti abdominis using diastasis recti test ${ }^{19}$.

Chiarello in their study Consequences of exercise regime on DRA in pregnant women resulted that about ninety percent of women who were not habitual of doing exercise or did not follow exercise regime had DRA and remaining who did exercise had only conditions. It was concluded that size and prevalence of DRA was more in non-exercising group than in exercising group of women ${ }^{20}$.

Chiarello conducted another research to compare inter rectus distance of pregnant women with pelvic girdle pain with these of other types of pregnancy related back pain, resulting in with inter rectus distance seen widest at umbilicus, narrowest below the umbilicus and decrease with a curl up, and showed no significant difference in the IRD of pregnant women with pelvic girdle pain ${ }^{21}$.

Monica conducted a multiple-baseline, single subject experimental design research on 16 women with lumbar pelvic pain after delivery and stated reduced pain and disability after an individually adjusted exercise intervention in women with post-delivery lumbar pelvic pain ${ }^{22}$.

Gerard conducted a study on functional therapeutic and core strengthening which postulated that athlete's core strength, endurance, coordination flexibility and balance has the role in optimal sports performance, As of medical literature support core stability as a prevention of injury. So, exercises that promote neuromuscular re-educate in athletes with core dysfunction are crucial to preventing and treating injury ${ }^{23}$.

Any pain or discomfort occurring in the low back region presently or a previous episode with a duration greater than 3 days within the last year that essential prolonged rest or medical consideration.

Low back pain usually arises in the region of lumbar, thoracolumbar, or lumbosacral. Back pain mostly effects working population. Back pain is Associated with many symptoms and functional limitations. It may be due to any soft tissue injury of the trunk including weakness or spasm or it occurs when the core muscle which is responsible for stabilization of lumbar region is weak ${ }^{2}$.

\section{METHODOLOGY}

142 Participants was recruited in our study. Participants signed consent form.

Questionnaires were filled by researcher after perform Kendell test.

\section{Study Design}

Study design was cross sectional study and information was collected using questionnaire.

\section{Study Population}

Men and women aged between 20 -40 years having back pain since 3 months.

\section{Inclusion Criteria ${ }^{2}$}

- Both gender male and female

- Age 20-40

- Having back pain

Exclusion Criteria ${ }^{13}$

- Pregnancy

- Spinal cord injuries.

- Neurological diseased

- Spondylosis

Red flag for back pain:

- Circulatory problems

- Tumors

- Infections

Yellow flag for back pain:

- Psychosocial problems

\section{Sampling Technique}

Non-probability Sampling Technique.

\section{Sample Size}

Sample size is calculated by using Epi software for sample size calculation. A study conducted at South Asia titled as "Participant in physical activity and back pain among an elderly population in South Asia" is used to calculate sample size.

\section{Study Setting}

- Tertiary care hospitals

\section{Study Duration}

3 months

\section{Assessment Protocol}

Back Patients were recruited from tertiary care hospitals after assessment and screening by consultants. Consent was taken from participants. Researcher re-examine patient and enrolled those who were met inclusion and exclusion criteria. Researcher filled self-administered questionnaire of those who fulfilled inclusion criteria. For rectus abdominis strength test researcher performed Kendell strength test and gave score as per performance.

\section{Kendall's Strength Test}

\section{- Kendall's Lower Abdominal Test}

is a test used to evaluate lower abdominal strength; subjects lie supine on a firm surface with arms folded across the chest; a tester assists in raising the legs up to a vertical position (subjects may actively raise one lower extremity at a time, if needed) keeping the knees straight; subjects then perform a posterior pelvic tilt and maintain this position while 
slowly lowering the legs to horizontal; strength is graded on the ability to keep the low back flat on the surface; the angle at which the back arches is noted and correlated with Kendall's grading system (Kendall et al., 1993) ${ }^{15}$.

\section{- Abdominal Strength Test}

is a test of upper abdominal strength; subjects are asked to lie supine on a firm surface with knees extended; a roll is placed under the knees if the subject displays a positive Thomas Test; the subject is then asked to place both hands behind the head and proceed to slowly curl up to a sitting position completing spinal flexion range of motion; if this action cannot be achieved, the subject modifies the arm positions and a grade is assigned per Kendall's muscle grading system (Kendall et al., 1993) ${ }^{15}$.

\section{Data Analysis}

SPSS Version 21 was used for data analysis. All categorical variables were used for jotting down frequencies and percentages. The association between two categorical variables was determined by applying chi-square test for significance. The significant P-value was less than 0.05

\section{Ethical Consideration}

- Confidential: Records of this study will be kept secured. Any information that patient tells us will remain confidential. The information's will be kept in a locked file; only the researchers for this study will have access to the records.

- Autonomy: participants were independent to take his or her decision to enroll in study.

- Beneficence: participants were requested to answer questions which may be private, but the data will not be shared with anyone else. Participants may refuse to answer any questions on the form. We will not share with anyone, the specific details you tell us.

- Justice: there was no harm of this research. Participants were included without any biasness

\section{RESULTS}

\section{Demographics}

In the following table-1, the means and standard deviations of participant's age and gender distribution is shown. There were in total 140 participants in this research study. The demographics showed the mean age of 29 years. There were $33.8 \%$ male and $66.2 \%$ female among participants.

Table1. Percentage distribution of demographic characteristics of back pain patients

\begin{tabular}{|c|c|c|}
\hline $\begin{array}{c}\text { Demographic } \\
\text { characteristics }\end{array}$ & $\mathrm{n}$ & $\%$ \\
\hline Age (Mean \pm SD) years & $29.01 \pm 5.76$ & \\
\hline Gender & & \\
\hline Male & 48 & 33.8 \\
\hline Female & 94 & 66.2 \\
\hline
\end{tabular}

Graph 1: gender distribution

\section{Gender distribution}

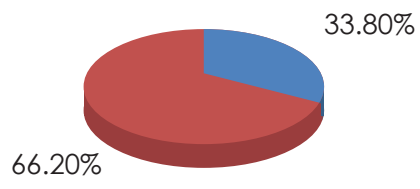

Male

Eemale

\section{Pain Characteristics of Participants}

Majority of participants were of acute back pain, followed by chronic back pain and most of the participants were not taking any medicine as shown in table 2 ,

Table 2 Percentage distribution of Pain characteristics of back pain patients

\begin{tabular}{|c|c|c|}
\hline Pain characteristics & $\mathrm{n}$ & $\%$ \\
\hline Duration of backache & & \\
\hline less than 6 weeks & 58 & 40.8 \\
\hline 6 to 12 weeks & 41 & 28.9 \\
\hline more than 12 weeks & 43 & 30.3 \\
\hline Taking any treatment & & \\
\hline Yes & 68 & 47.9 \\
\hline No & 74 & 52.1 \\
\hline
\end{tabular}

Pain intensity was assessed on NPRS scale and most participants of the study were having moderate pain followed by mild pain as shown in table 3

\begin{tabular}{|c|c|c|}
\hline \multicolumn{3}{|c|}{$\begin{array}{c}\text { Table3. Percentage distribution of Pain Severity } \\
\text { among back pain patients }\end{array}$} \\
\hline Pain Severity & $\mathrm{n}$ & $\%$ \\
\hline Pain(Mean \pm SD) years & $5.16 \pm 2.53$ & \\
\hline Severity of pain & & \\
\hline Mild & 52 & 36.6 \\
\hline Moderate & 61 & 43.0 \\
\hline Severe & 29 & 20.4 \\
\hline
\end{tabular}

\section{Kendall's Abdominal Test Score}

Upper abdominal test score of most of the participant have grade 3 fair grade muscle power (45.8\%) followed by grade 2 poor muscle power (37.3\%) which was found statistically non-significant at $\mathrm{P}<0.509$ (table 4).

Table 4. Kendall's Upper Abdominal test score

\begin{tabular}{|c|c|c|c|c|}
\hline $\begin{array}{c}\text { Upper Abdominal } \\
\text { test }\end{array}$ & $\mathbf{N}$ & $\boldsymbol{\%}$ & $\begin{array}{c}\text { Chi- Square } \\
\text { Tests }\end{array}$ & P value \\
\cline { 1 - 3 } Poor & 53 & 37.3 & 5.276 & 0.509 \\
\hline Fair & 65 & 45.8 & & \\
\hline Good & 20 & 14.1 & & \\
\hline Normal & 4 & 2.8 & & \\
\hline
\end{tabular}

While performing lower abdominal test most participant have grade 3 (fair grade) muscle power (50\%) followed by grade 4 (good) muscle power (31.7\%) which was found statistically significant at $\mathrm{P}<0.016$, (table 5). 
Table5. Kendall's Lower Abdominal test score

\begin{tabular}{|c|c|c|c|c|}
\hline $\begin{array}{c}\text { Lower Abdominal } \\
\text { test score }\end{array}$ & $\mathbf{N}$ & $\%$ & $\begin{array}{c}\text { Chi- Square } \\
\text { Tests }\end{array}$ & P value \\
\hline Poor & 20 & 14.1 & 15.562 & 0.016 \\
\hline Fair & 71 & 50.0 & & \\
\hline Good & 45 & 31.7 & & \\
\hline Normal & 6 & 4.2 & & \\
\hline
\end{tabular}

When we correlate the back pain and power/strength of rectus abdominis there were no correlation shown between back pain and rectus abdominis power/strength. (table 6)

Table 6. Spearman's rho correlation pain score with Kendall's Upper Abdominal test score and Kendall's Lower Abdominal test score

\begin{tabular}{|c|c|c|}
\hline Spearman's rho & $\begin{array}{c}\text { Kendall's Upper } \\
\text { Abdominal test } \\
\text { score }\end{array}$ & $\begin{array}{c}\text { Kendall's Lower } \\
\text { Abdominal test } \\
\text { score }\end{array}$ \\
\hline $\begin{array}{c}\text { Correlation } \\
\text { Coefficient }\end{array}$ & 0.065 & -0.031 \\
\hline Sig. (2-tailed) & 0.439 & 0.712 \\
\hline $\mathbf{N}$ & 142 & 142 \\
\hline
\end{tabular}

\section{Kendall's abdominal strength test}

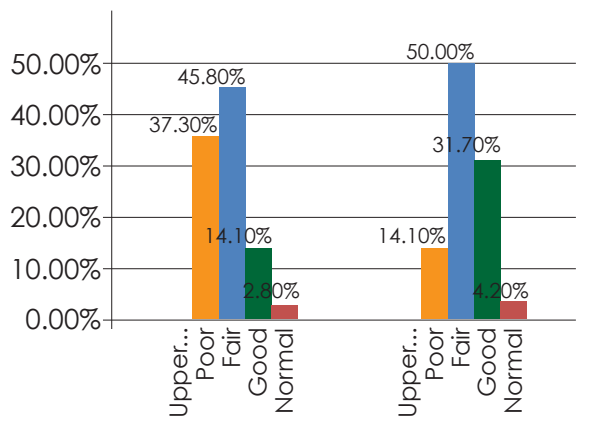

\section{DISCUSSION}

Back pain considers expensive disease in modern society. There are many causes/risks that leading to the occurrence of back pain. A cross sectional study was conducted to evaluate contribution of rectus abdominis muscle in the patients with the complain of back pain. This study included 142 patients who were diagnosed with back pain, without any serious pathology.

In this study, both genders participants were included. It was found that female participants ratio was high in comparison to male participants. Buchbinder (2013) in their systemic review stated that women suffered with back pain more than men24, whereas in other study Hoy (2014) stated that, men are more prone to have back pain than women ${ }^{25}$.

The participants age group were between 20-40 years were included in this study, keeping in view Shiri study (2010) who concluded that Low back pain is common in participants ages between 24 -39 years $^{26}$.

In the current study Kendall, upper abdominal and Kendall lower abdominal test were used as outcome measure to assess muscle power of abdominal muscles. MacDonald (1998) concluded in his pilot study on 63 that there is increased incidence of low back pain that has been related with Lumbar lordosis, especially in women. The posture stretches and weakens the abdominals (rectus abdominis, external and internal oblique's) while shortening the hip flexors and lumbar extensors imbalance increases the stress to the low back, resulting in pain. He conducted fitness test among school going children. He conducted Kendall's lower abdominal and Kendall's upper abdominal test to check the strength of rectus abdominis muscle ${ }^{15}$. In the current study, no relation found back pain patients and weakness of rectus abdominis. MOTA (2014) in her research concluded that women with DRA were not prone to develop back pain than women without DRA, this study support the present study ${ }^{14}$. In another study by Joran (2016) showed no difference between women with and without DRA, and prevalence of low back and/or pelvic girdle pain ${ }^{27}$. According to Stephanie Mulhearn there is some evidence of a link between low back pain, postural muscle endurance in gymnasts and no cause and effect relationship determined $^{28}$.

On the contrary, Dalal khushboo (2014) conducted research on 30 women aged greater than 18 years to find correlation between diastasis rectus abdominis and lumbopelvic pain. Subjects were assessed on the Pelvic Floor Distress Inventory, Modified Oswestry Low Back Pain Disability Questionnaire, Visual Analog Scales (VAS) for pain. Diastasis Rectus Abdominis measurement was taken. Dalal concluded that the incidence for the DRA was $83.33 \%$, and women with a DRA tend to have more lumbo-pelvic pain $^{29}$

The strength of the study was, it was a randomized control trail, single blindness, both genders were included in the study, and it was multi-centered study. The weakness of study is non-back pain patients were not included in the study so no comparison could have done between health and back pain patients.

\section{CONCLUSION}

In the current study, the prevalence of back pain is higher in females. There was no correlation found between back pain and rectus abdominis 


\section{REFERENCES}

[1] Arslan SA, Hadian MR, Olyaei G, Bagheri H, Yekaninejad MS, ljaz S, Kheradmand AA. Prevalence and Risk Factors of Low Back Pain Among the Office Workers of King Edward Medical University Lahore, Pakistan. PTJ. 2016;6(3):161-168

[2] Lee M, Song C, Jo Y, Ha D, Han D. The effects of core muscle release technique on lumbar spine deformation and low back pain. J Phys Ther Sci. 2015;27(5):1519-22

[3] Meucci RD, Fassa AG, Faria NM. Prevalence of chronic low back pain: systematic review. Rev Saude Publica. 2015;49

[4] Mostagi FQ, Dias JM, Pereira LM, Obara K, Mazuquin BF, Silva MF, Silva MA, de Campos RR, Barreto MS, Nogueira JF, Lima TB. Pilates versus general exercise effectiveness on pain and functionality in non-specific chronic low back pain subjects. J Bodyw Mov Ther. 2015;19(4):636-45

[5] Hirata RP, Salomoni SE, Christensen SW, Graven-Nielsen T. Reorganised motor control strategies of trunk muscles due to acute low back pain. Hum Mov Sci. 2015;41:282-94

[6] Bishwajit G, Tang S, Sanni Yaya ZF. Participation in physical activity and back pain among an elderly population in South Asia. J Pain Res. 2017; 10:905

[7] Zanuto EA, Codogno JS, Christófaro DG, Vanderlei LC, Cardoso JR, Fernandes RA. Prevalence of low back pain and associated factors in adults from a middle-size Brazilian city. Cien Saude Colet. 2015;20(5):1575-82

[8] Nelson-Wong E, Callaghan JP. Is muscle co-activation a predisposing factor for low back pain development during standing? A multifactorial approach for early identification of at-risk individuals. J Electromyography Kinesiol. 2010;20(2):256-63

[9] Meucci RD, Fassa AG, Paniz VM, Silva MC, Wegman DH. Increase of chronic low back pain prevalence in a medium-sized city of southern Brazil. BMC Musculoskelet Disord. 2013;14(1):155

[10] Acharry N, Kutty RK. Abdominal exercise with bracing, a therapeutic efficacy in reducing diastasis-recti among postpartal females. Physiother Res Int. 2015;3(2):999-1005

[11] Gray J, Aginsky KD, Derman W, Vaughan CL, Hodges PW. Symmetry, not asymmetry, of abdominal muscle morphology is associated with low back pain in cricket fast bowlers. J Sports Sci Med. 2016;19(3):222-6

[12] Silfies SP, Squillante D, Maurer P, Westcott S, Karduna AR. Trunk muscle recruitment patterns in specific chronic low back pain populations. Clin Biomech . 2005;20(5):465-73

[13] Correia JP, Oliveira R, Vaz JR, Silva L, Pezarat-Correia $P$. Trunk muscle activation, fatigue and low back pain in tennis players. J Sports Sci Med. 2016;19(4):311-316
[14] Da Mota PG, Pascoal AG, Carita Al, Bø K. Prevalence and risk factors of diastasis recti abdominis from late pregnancy to 6 months postpartum, and relationship with lumbo-pelvic pain. Man Ther. 2015;20(1):200-5

[15] McDonald GL, Nederveld KL. The Effects of Abdominal Strength Exercises and Testing on Posture in School Children.1998. Available from: https://scholarworks.gvsu.edu/theses/409

[16] Benjamin DR, Van de Water AT, Peiris CL. Effects of exercise on diastasis of the rectus abdominis muscle in the antenatal and postnatal periods: a systematic review. Physiotherapy. 2014;100(1):1-8

[17] Clark AW, Goedeke MK, Cunningham SR, Rockwell DE, Lehecka BJ, Manske RC, Smith BS. Effects of pelvic and core strength training on high school cross-country race times. J Strength Cond Res. 2017;31(8):2289-95

[18] Rett MT, Braga MD, Bernardes NO, Andrade SC. Prevalence of diastasis of the rectus abdominis muscles immediately postpartum: comparison between primiparae and multiparae. Braz J Phys Ther. 2009;13(4):275-80

[19] Shah SK, Honkalas P, Kumar A. Correlation of Low Back Pain and Diastasis Rectus Abdominis in Post-Menopausal Women between the Age Group of 50-60 Years. Indian J Physiother Occup Ther. 2016;10(3):108-11

[20] Chiarello CM, McAuley JA, Hartigan EH. Immediate effect of active abdominal contraction on inter-recti distance. J Orthop Sports Phys Ther. 2016;46(3):177-83

[21] Chiarello CM. Pregnancy-Related Pelvic Girdle Pain and Diastasis Rectus Abdominis. J Womens Health Phys Therap. 2017;41 (1):3-9

[22] Unsgaard-Tøndel M, Vasseljen $O$, Woodhouse A, Mørkved S. Exercises for women with persistent pelvic and low back pain after pregnancy. Glob J Health Sci. $2016 ; 8(9): 107$

[23] Malanga GA, Aydin SM, Holder EK, Petrin Z. Functional Therapeutic and Core Strengthening. In The Hip and Pelvis in Sports Medicine and Primary Care 2017 (pp. 185-214). Springer International Publishing.

[24] Buchbinder R, Blyth FM, March LM, Brooks $P$, Woolf AD, Hoy DG. Placing the global burden of low back pain in context. Best Pract Res Clin Rheumatol. 2013; 27(5):575-89

[25] Hoy D, March L, Brooks P, Blyth F, Woolf A, Bain C, Williams G, Smith E, Vos T, Barendregt J, Murray C. The global burden of low back pain: estimates from the Global Burden of Disease 2010 study. Ann Rheum Dis. 2014: 73(6):968-974

[26] Shiri R, Solovieva S, Husgafvel-Pursiainen K, Viikari J, Raitakari OT, Viikari-Juntura E. Incidence of nonspecific and radiating low back pain: followup of 24-39-year-old adults of the Young Finns Study. Arthritis care Res. 2010;62(4):455-9

[27] Sperstad JB, Tennfjord MK, Hilde G, Ellström-Engh $M, B \varnothing K$. Diastasis recti abdominis during pregnancy and 12 months after childbirth: preva- 
lence, risk factors and report of lumbopelvic pain. Br J Sports Med. 2016:

[28] Mulhearn S, George K. Abdominal muscle endurance and its association with posture and low back pain: An initial investigation in male and female elite gymnasts. Physiotherapy.
1999;85(4):210-6

[29] Dalal K, Kaur A, Mitra M. Correlation between diastasis rectus abdominis and lumbopelvic pain and dysfunction. Indian J Physiother Occup Ther. 2014;8(1):210 